\title{
BMJ Open Comprehensive assessment of health education and health promotion in five non-communicable disease demonstration districts in China: a cross-sectional study
}

Qiaohua Xu, Yuelong Huang, Biyun Chen

To cite: $X u$ Q, Huang $Y$, Chen B. Comprehensive assessment of health education and health promotion in five non-communicable disease demonstration districts in China: a crosssectional study. BMJ Open 2017;7:e015943. doi:10.1136/ bmjopen-2017-015943

- Prepublication history and additional material for this paper are available online. To view these files, please visit the journal online (http://dx.doi org/10.1136/bmjopen-2017015943).

Received 25 January 2017 Revised 3 October 2017 Accepted 19 0ctober 2017

CrossMark

Department of Chronic Disease Control and Prevention, Hunan Provincial Centre for Diseases Control and Prevention, Changsha, China

Correspondence to

Dr Qiaohua Xu;

xqh301717@sina.com

\section{ABSTRACT}

Objectives This study aims to develop assessment indicators of health education and promotion for noncommunicable disease (NCD) demonstration districts in China and to identify significant factors associated with NCD health education and promotion work.

Methods Three complementary techniques were used to conduct this study in Hunan Province, China, between late 2013 and 2015. The Delphi technique was used to develop weighted assessment indicators, followed by the rank sum ratio (RSR) to normalise the weights through rank conversion. Lastly, the technique for order of preference by similarity to ideal solution was conducted to assess five randomly selected NCD demonstration districts representing five different orientations in the province. Results A total of 24 assessment indicators were constructed covering the following sections: organisational management, fund support, personnel supplies, health education and promotion, people's awareness of NCDs, management and control of patients with NCD, satisfaction with health education and promotion and health literacy of residents. Five districts were selected as samples for evaluation (Furong District, Ziyang District, Shaodong County, Shuangfeng County and Luxi County). Performance varied among the sites, with Furong District greatly surpassing the other sites, especially in fund support, media promotion, technical support for publicity materials, community promotion and supportive environment supplies. The latter four factors were also much greater in the second-ranked Luxi County site than those in the other sites (except Furong District).

Conclusions There were gaps in health education and promotion work in NCD demonstration districts in Hunan Province. The districts that performed better had obvious advantages in fund support, media promotion, technical support, community promotion and supportive environment supplies. Our study provided both a methodological reference and an assessment indicator framework for similar future studies.

\section{INTRODUCTION}

China has undergone a swift health transition over the past two decades. Currently, the
Strengths and limitations of this study

- To the best of the authors' knowledge, this study is the first to build assessment indicators for health education and promotion in non-communicable disease (NCD) demonstration districts in China.

- This study used three popular assessment tools (Delphi, rank sum ratio and technique for order of preference by similarity to ideal solution) that are both qualitative and quantitative and hence provide a methodological reference for similar future studies.

- One limitation of this study was that fewer NCD demonstration districts were selected as evaluation samples and thus failed to fully reflect the whole situation in China.

- Another limitation was the cross-sectional design and lack of control data from either the history of those districts or non-NCD demonstration districts.

spectrum of people's diseases is dominated by non-communicable diseases (NCDs) (also known as chronic diseases), such as cardiovascular diseases, lung cancer, chronic obstructive pulmonary disease and road injuries, ${ }^{1}$ instead of infectious diseases. This transition has resulted in a rapid increase in the incidence of these diseases and a heavy disease burden. Currently, approximately 260 million Chinese accounting for $19 \%$ of the nation's population suffer from NCDs, which contribute to $85 \%$ of the mortality rate and $70 \%$ of the disease burden. ${ }^{2}$ Thus, China is facing great challenges from NCDs.

The National Health and Family Planning Commission of China (NHFPC, the former Ministry of Health) launched a nationwide NCD demonstration district (or county) programme in late 2010 that was similar to the widely known health cities that were designated in many countries in the late $1980 \mathrm{~s}^{3}$ The programme aimed to create 
an exemplary effect of NCD demonstration districts for other regions and to promote NCD control and prevention across the country. In the principle of voluntary, stepby-step declaration, areas that wanted to become national NCD demonstration districts had to obtain a recommendation from the provincial health administration department and then pass an assessment organised by the NHFPC. Similarly, the declaration of provincial NCD demonstration districts went through a city-level recommendation first and then a provincial assessment.

Health education is defined as a systematic social activity that helps people improve their health-related behaviours. For NCDs, health education often involves publicising a healthy lifestyle, such as non-smoking, a low-salt diet, a proper diet, adequate physical activities and mental health, using publicity materials, billboard, lectures and media promotion. Health promotion is the process of enabling people to increase control over and improve their health. ${ }^{4}$ The Ottawa Charter for health promotion action includes the following five policies ${ }^{4}$ : building a healthy public policy (eg, raising the tobacco excise tax), creating supportive environments (eg, building a fitness trail), strengthening community actions, developing personal skills and reorienting health services. Integrated health education and promotion are the first priorities of the policy and the primary means of NCD control and prevention; thus, these policies play important roles in NCD demonstration district programmes. However, the work is relatively new in China, and only rare systematic assessments have been reported (ie, no assessment indicators are available). Thus, based on health education and promotion in the districts, this study was conducted to develop assessment indicators, compare the performances among districts and analyse important factors for health education and promotion to provide a framework or methodological reference for other health studies.

\section{METHODS \\ Study design}

Three evaluation techniques were comprehensively followed in the study. Figure 1 shows the flow diagram. A modified Delphi method originally developed by Kathryn Fitch $^{5}$ was used in the following steps (conducted between late 2013 and 2014):

1. Thirty-nine subsectional consultative items in seven sections were selected for the first Delphi round based on the work manuals of the NCD demonstration districts developed by the Chinese Centre for Disease Control and Prevention (China CDC) and our own work experiences (see online supplementary appendix table A1).

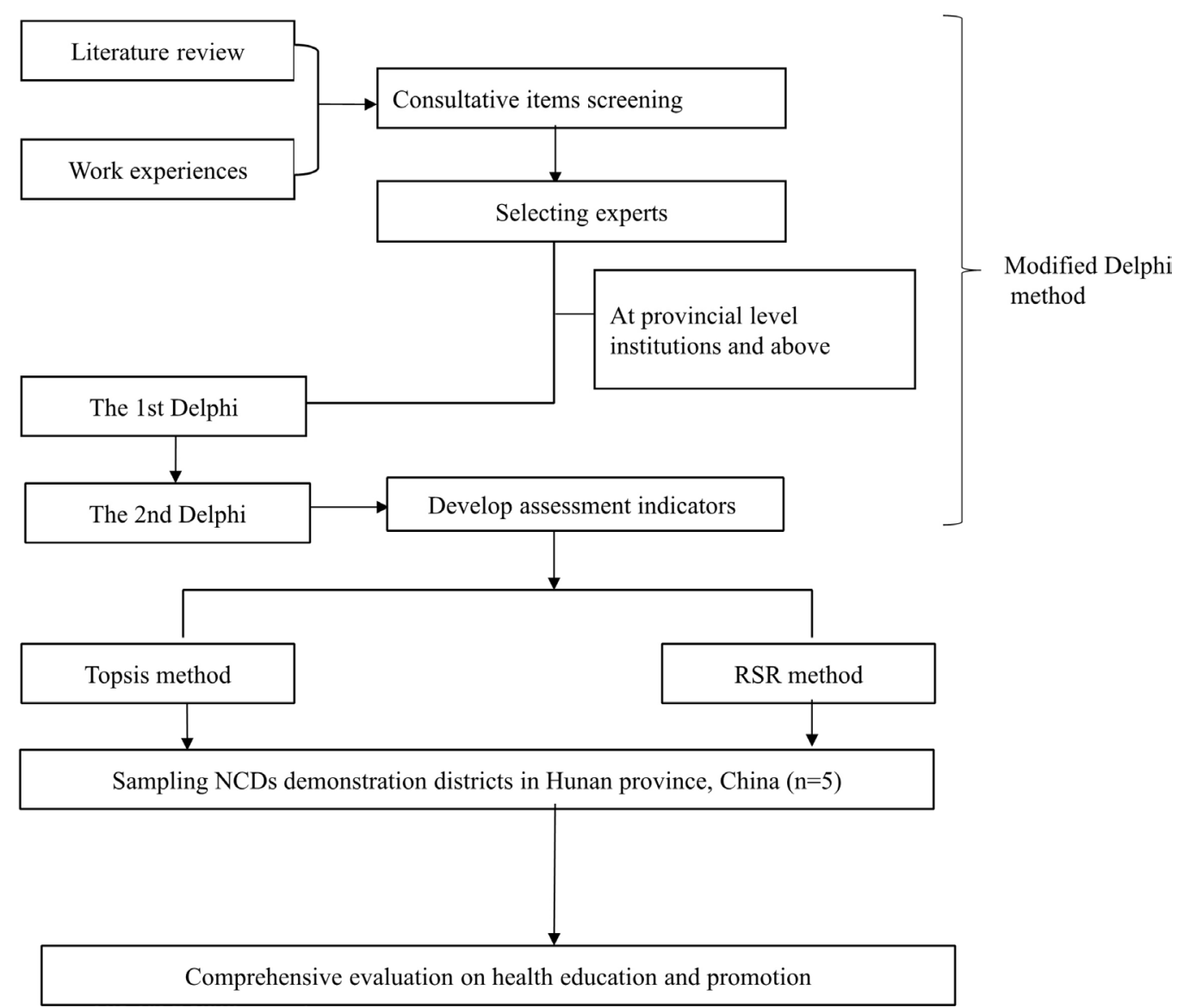

Figure 1 Study flow diagram. NCDs, non-communicable diseases; RSR, rank sum ratio; TOPSIS, technique for order of preference by similarity to ideal solution. 
2. Experts nationwide were invited if they met the following demands: worked in NCD control and prevention, health education and promotion or other public health professions, worked for provincial or national institutions with 5 years or more of work experience and showed an interest in participating in the study.

3. A two-round Delphi process was conducted. In the first round, experts were asked to judge whether items should be included and were free to add items or make comments. The experts scored each item using a 9-point Likert scale (1-9: extremely unimportant to extremely important).$^{6-8}$ The data were summarised, revised and sent to experts for a second round following the same format as the first round. Then, the assessment indicators were determined.

Second, the rank sum ratio (RSR) method introduced by $\operatorname{Tian}^{9}$ was followed (conducted in 2015). The basic theory behind the method is that a dimensionless statistical indicator is calculated from an $\mathrm{n} \times \mathrm{m}$ matrix using rank conversion. The subjects' statuses (worst/best) were evaluated using the RSR order. All items were first ranked as $(i \leq n, j \leq m)$, with the higher quality items ranked in ascending order and the lower quality items ranked in descending order. Then, a weighted RSR was calculated with the equation

$$
R S R_{i}=\frac{\sum_{j=1}^{m} R_{i j}}{m \times n} .
$$

Finally, the technique for order of preference by similarity to ideal solution (TOPSIS) ${ }^{10-12}$ was employed to assess the sampled NCD demonstration districts (conducted in 2015). Prior to the technique, some NCD districts were chosen as evaluation samples. To ensure a balanced geographic distribution of the districts, we randomly selected five districts representing different orientations (south, north, east, west and middle) out of the total 28 districts in the province and generated the following districts as samples with a randomising function in Microsoft Excel 2010: Furong District, Ziyang District, Shaodong County, Shuangfeng County, and Luxi County. The assessment indicator data were collected between 2014 and 2015 from the above districts. TOPSIS was conducted using the following six steps:

1. The original values of items $(\mathrm{Xij})$ were converted to the high-quality (X'ij) values. However, there was no need to convert the values here due to their natural high-quality features.

2. The mono-trended matrix was normalised as Yij and calculated using the equation $Y_{i j}=X_{i j}^{\prime} \div \sqrt{\sum_{i=1}^{m}\left(X_{i j}^{\prime}\right)^{2}}$.

3. Based on the weights introduced by RSR, the combined values of the normalised matrix were calculated as $Z_{i j}$ using the equation $Z_{i j}=R S R_{i}{ }^{*} Y_{i j}$.

4. The ideal solution $(A+)$ and negative ideal solution $(A-)$ were determined.
5. The distance of each alternative to the ideal $(D i+)$ and negative ideal $(\mathrm{Di}-)$ solutions and the relative similarities of an alternative to the ideal solution $(C i)$ were calculated.

6. The alternatives were ranked based on $\mathrm{Ci}$. A larger $\mathrm{Ci}$ indicated a greater alternative.

\section{Statistical analyses}

During the Delphi process, the assessment items were excluded unless they simultaneously reached expert agreement $(\%) \geq 70 \%,{ }^{13-15}$ a median score $\geq 7^{16-18}$ and a coefficient of variation (CV) $<0.25 .^{19}{ }^{20}$ The internal consistency of the items was evaluated with Cronbach's $\alpha$ coefficient test. A Cronbach's $\alpha$ of 0.7 or greater was regarded as reasonable reliability, and a value of 0.8 or greater was regarded as good reliability. ${ }^{21-23}$

The data were analysed from 2014 to 2015 . The variable mean, SD, CV and Cronbach's $\alpha$ were analysed with SPSS V.17.0. Other related data obtained from the above methods were addressed using Microsoft Excel 2010.

\section{RESULTS}

In total, 19 experts (figure 2) from national or provincial public health institutions completed the Delphi process. Most of the experts (68.42\%) came from the CDC. The experts had been working for a mean of $15.53 \pm 7.40$ years, and approximately $90 \%$ of the experts had been awarded honours as senior doctors. All the experts had bachelor degrees in public health, and $63 \%$ of the experts had master's degrees.

The two-round Delphi process (table 1) removed 15 items, including 14 in the first round and one in the second round. Twenty-four items remained as assessment indicators with scores defined as weights (see online supplementary appendix A2), which covered the following sections: organisational management, fund support, personnel supplies, health education and promotion, awareness of NCDs, satisfaction with health education and promotion and health literacy of residents.

The Cronbach's $\alpha$ value in the first Delphi round was 0.90 with a $95 \%$ CI of 0.82 to 0.95 , whereas the Cronbach's $\alpha$ in the second round was 0.85 (95\% CI 0.74 to 0.93 ). Thus, both rounds exhibited good internal consistency.

The RSR method was used to normalise the indicator weights provided by the modified Delphi method (table 2).

Prior to the TOPSIS technique, five NCD demonstration districts were randomly sampled as follows: one national level NCD demonstration district (Furong District) and four provincial level districts (Ziyang District, Shaodong County, Shuangfeng County and Luxi County). Then, the TOPSIS technique was used to normalise the real values of the assessment indicators in the sample districts and to calculate combined indicator values (table 2 ). 


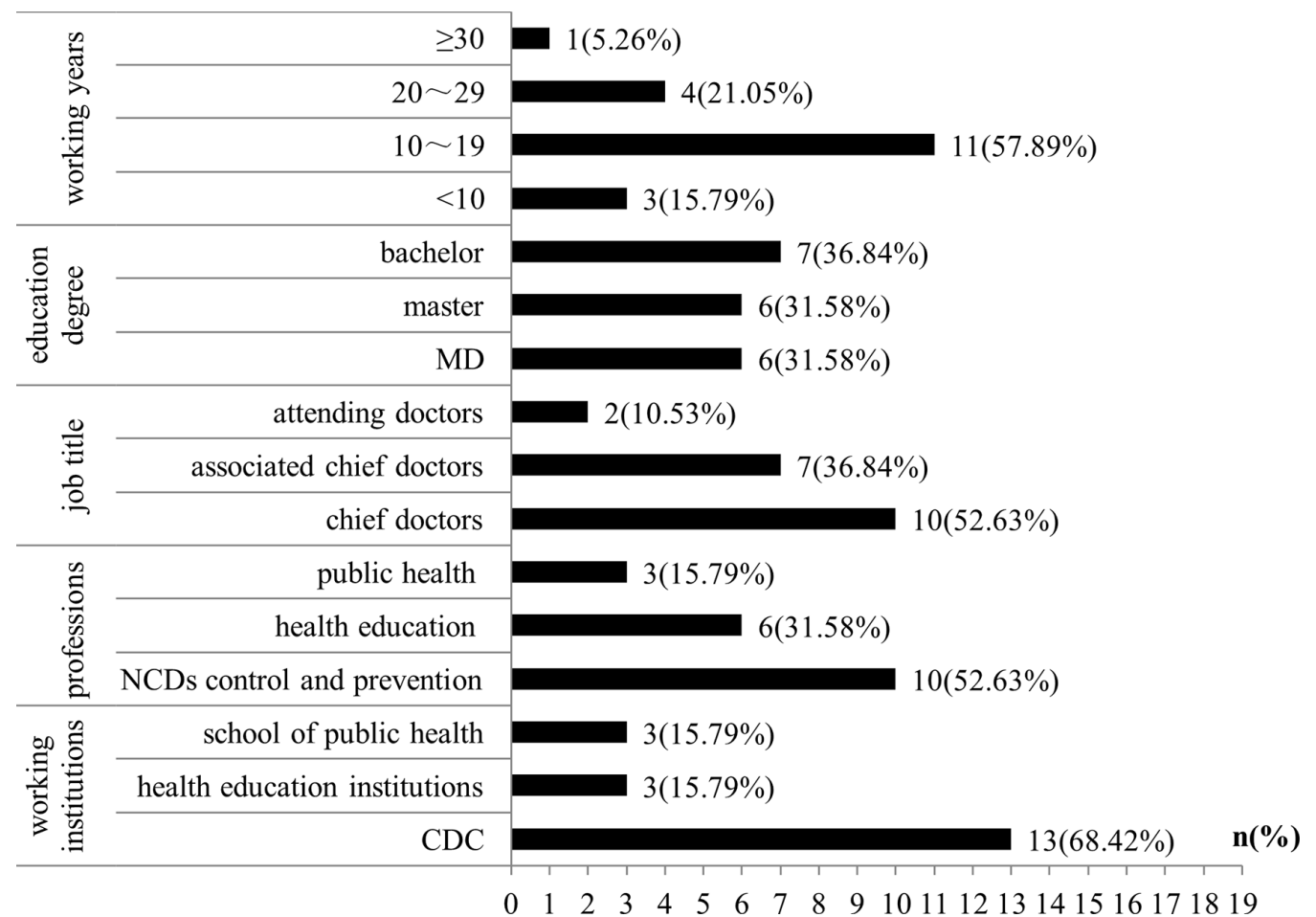

Figure 2 Characteristics of the experts who participated in the Delphi process. CDC, Centre for Disease Control and Prevention; MD, Doctor of Medicine; NCDs, non-communicable diseases.

Finally, the five sample districts were ranked in order (from best to worst) as Furong District $>$ Luxi County $>$ Ziyang District $>$ Shaodong County $>$ Shuangfeng County, with Furong District greatly surpassing the other areas with the highest $\mathrm{Ci}$ (table 3).

\section{DISCUSSION}

Multiassessments should be comprehensively employed in health evaluations due to features such as objects, purposes and data types to compensate for the limitations of a single assessment. With features including anonymity, iteration, controlled feedback and statistical summarisation, the Delphi technique was chosen as a suitable method for obtaining collective expert opinions because this method was widely used in health-related research. ${ }^{152425}$ TOPSIS, which was developed by Hwang and Yoon, ${ }^{26}$ was chosen as a family member of multiple-criteria decision-making. ${ }^{27-29}$ This method provides an optimal solution or alternative ranking ${ }^{30}$ without operational issues or limitations on data types ${ }^{31-33}$ but often fails to avoid the impact of abnormal values. ${ }^{34}$ The RSR method is based on a non-parameter analysis and has no data type restrictions. Moreover, RSR can eliminate the bias of abnormal values by reflecting the priority of the evaluated objects. ${ }^{35}$

The above methods were used in this study to construct assessment indicators and to evaluate the health education and promotion situations in the NCD demonstration districts. The results showed that the Furong District obviously surpassed the other districts, especially in fund support, media promotion, technical support for promotion materials, community promotion and supportive environment supplies and matched the national level nomination. As a central district in the capital city of Hunan Province, the main economic indicators of Furong were among the best of the counties/ districts in the province. ${ }^{3637}$ Local government supported much of the NCD control and prevention-related funds. Both the fees for NCD health education and promotion and proportion of NCD control expenditures in total business expenses in the local CDC were also advantages and provided a strong basis for conducting relevant work. Additionally, this district has been historically solid in health education and promotion, with the 'Ten health projects', such as total health mobilisation and a massive health auditorium. Furong was also leading in building a rich-themed NCD health education database among grass-level medical institutions and information sharing models, which greatly benefited the residents, whose awareness rates, satisfaction and health literacy levels for NCDs were all superior compared with the levels of the residents of the other districts.

Following Furong District, Luxi County ranked second with its own features. This county is regarded as one of the Wuling Mountain Areas Regional Development Key counties and is a national poverty-stricken county, ${ }^{38}$ with insufficient funds for NCD control and prevention supported by the local government. The other two fund guarantees were also dwarfed by the other districts. However, Luxi County was comprehensive in conducting methods and extensive in its NCD control and prevention themes despite having a simple external form, which 
Table 1 Results from the two-round Delphi process

\section{Round 1}

Round 2

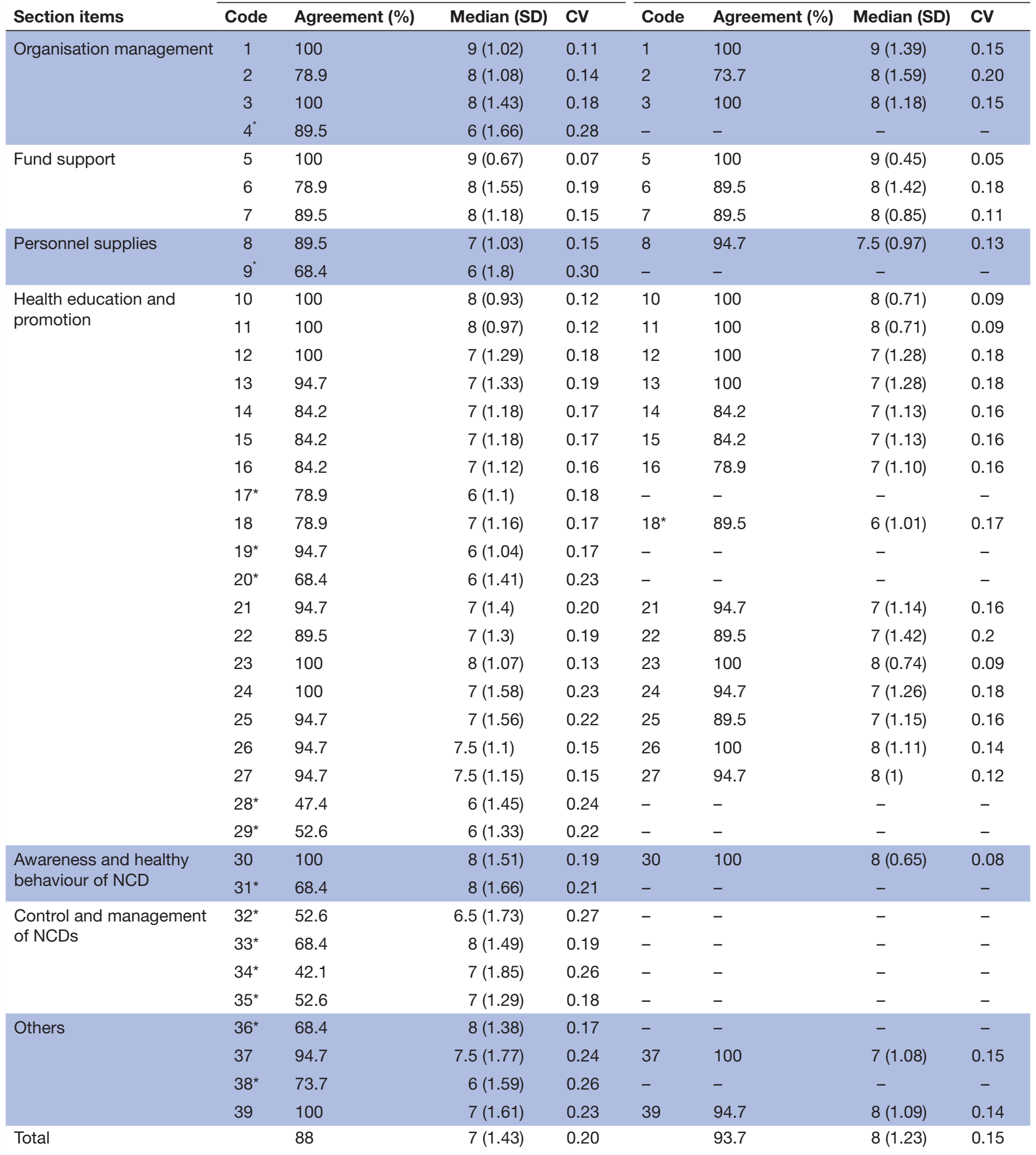

*Items removed in each round.

$\mathrm{CV}$, coefficient of variation; NCDs, non-communicable diseases.

highlighted its diverse and frequent media promotion strategies (particularly with television stations, with an annual 44 period showing for an average of $30 \mathrm{~min}$ per time). NCD education and promotion permeated into every village or community, featuring $100 \%$ coverage of fitness centres or rooms and numerous types of NCD 
Table 3 Ranking of the sample districts in Hunan province by TOPSIS

\begin{tabular}{lllll}
\hline Subject & D+ & D- & Ci & Rank \\
\hline Furong District & 0.0376 & 0.0716 & 0.6558 & 1 \\
Luxi County & 0.0663 & 0.0458 & 0.4085 & 2 \\
Ziyang District & 0.0628 & 0.0332 & 0.3462 & 3 \\
Shaodong County & 0.0744 & 0.0277 & 0.2712 & 4 \\
Shuangfeng County & 0.0672 & 0.0248 & 0.2693 & 5 \\
\hline
\end{tabular}

TOPSIS, technique for order of preference by similarity to ideal solution.

promotion materials, gaining an advantage over other objects (except for Furong District).

The middle-ranking Ziyang District had the most assessment indicators at the middle level. In the last two ranked objects, the comprehensive performances of both Shaodong and Shuangfeng counties were lacking, which might have been a result of their late beginning and hasty NCD demonstration district processes during the study period as well as a historically unsolid work basis.

\section{CONCLUSIONS}

We built qualitative and quantitative assessment indicators of health education and promotion in NCD demonstration districts using a hybrid of multiassessment methods to provide a valid reference for future similar studies. There were gaps in health education and promotion work in the NCD demonstration districts in Hunan province. The districts that performed better had obvious advantages in fund support, media promotion, technical support, community promotion and supportive environment supplies. The variances were associated with local fund support and with the working basis within the district. Fund support did not always influence the variances because the limitation of inadequate fund support could be broken and even shifted into an advantage with a solid working quality.

Acknowledgements We are grateful to all experts who participated in the Delphi process. We also thank the Furong District CDC, Ziyang District CDC, Shaodong County CDC, Shuangfeng County CDC and Luxi County CDC for their great work in assisting with the data collection and survey conduction.

Contributors QX contributed to the study design, conducted the study, analysed the data and wrote the manuscript. YH was the principal guarantor of the study and contributed to the study design. BC managed the study day-to-day and commented on manuscript writing. All authors have discussed the paper and approved the final version.

Funding This work was supported by China Hunan Provincial Science \& Technology Department (No. 2013zk2054).

Competing interests None declared.

Patient consent Obtained.

Ethics approval This study was approved by the Ethics Committee of Hunan Provincial Centre for Disease Control and Prevention, China (HNCDC/JL31-044: 2013011).

Provenance and peer review Not commissioned; externally peer reviewed.

Data sharing statement No additional data available.
Open Access This is an Open Access article distributed in accordance with the Creative Commons Attribution Non Commercial (CC BY-NC 4.0) license, which permits others to distribute, remix, adapt, build upon this work non-commercially, and license their derivative works on different terms, provided the original work is properly cited and the use is non-commercial. See: http://creativecommons.org/ licenses/by-nc/4.0/

(c) Article author(s) (or their employer(s) unless otherwise stated in the text of the article) 2017. All rights reserved. No commercial use is permitted unless otherwise expressly granted.

\section{REFERENCES}

1. Yang G, Wang Y, Zeng Y, et al. Rapid health transition in China, 19902010: findings from the global burden of disease study 2010. Lancet 2013:381:1987-2015.

2. Information Office of the State Council. Medical and Health Services in China. Beijing, China: Foreign Language Press, 2012.

3. Lee A, Cheng FF, Fung Y, et al. Can health promoting schools contribute to the better health and wellbeing of young people? The Hong Kong experience. J Epidemiol Community Health 2006;60:530-6.

4. Word Health Organization. Ottawa charter for health promotion. Can $J$ Public Health 1986;77:425-30.

5. Fitch K, Bernstein SJ, Aguilar MD, et al. The RAND/UCL Appropriateness Method User's Manual. Santa Monica, CA: RAND, 2001.

6. Suzuki Y, Fukasawa M, Nakajima S, et al. Development of disaster mental health guidelines through the Delphi process in Japan. Int $J$ Ment Health Syst 2012;6:7.

7. Mrowietz $\mathrm{U}$, de Jong EM, Kragballe $\mathrm{K}$, et al. A consensus report on appropriate treatment optimization and transitioning in the management of moderate-to-severe plaque psoriasis. J Eur Acad Dermatol Venereol 2014;28:438-53.

8. Konstantinou K, Hider SL, Vogel S, et al. Development of an assessment schedule for patients with low back-associated leg pain in primary care: a Delphi consensus study. Eur Spine $J$ 2012;21:1241-9.

9. Sun ZQ, Tian FD. Medical systematic evaluation. Beijing, China: China Sci and Technol Press, 1994.

10. Fang JQ. Health Statistics (6th ed): Beijing, China People's Medical Publishing house, 2008:428-31.

11. Opricovic S, Tzeng G-H. Compromise solution by MCDM methods: a comparative analysis of VIKOR and TOPSIS. Eur J Oper Res 2004;156:445-55.

12. Jahanshahloo GR, Lotfi FH, Izadikhah M. An algorithmic method to extend TOPSIS for decision-making problems with interval data. Appl Math Comput 2006;175:1375-84.

13. Booth $A$, Clarke M, Ghersi D, et al. Establishing a minimum dataset for prospective registration of systematic reviews: an international consultation. PLoS One 2011;6:e27319.

14. Chipchase LS, Buttrum PJ, Dunwoodie R, et al. Characteristics of student preparedness for clinical learning: clinical educator perspectives using the Delphi approach. BMC Med Educ 2012;12:112.

15. Robinson KR, Leighton $P$, Logan $P$, et al. Developing the principles of chair based exercise for older people: a modified Delphi study. BMC Geriatr 2014;14:65.

16. Benhamou M, Baron G, Dalichampt M, et al. Development and validation of a questionnaire assessing fears and beliefs of patients with knee osteoarthritis: the knee osteoarthritis fears and beliefs questionnaire (KOFBeQ). PLoS One 2013;8:e53886.

17. Slade SC, Dionne CE, Underwood M, et al. Standardised method for reporting exercise programmes: protocol for a modified Delphi study. BMJ Open 2014:4:e00682.

18. Taylor RM, Feltbower RG, Aslam N, et al. Modified international e-Delphi survey to define healthcare professional competencies for working with teenagers and young adults with cancer. BMJ Open 2016;6:e011361.

19. Muñoz Fernández S, Lázaro y De Mercado P, Alegre López J, et al. Quality of care standards for nursing clinics in rheumatology. Reumatol Clin 2013;9:206-15.

20. Bao H, Yang F, Wang X, et al. Developing a set of quality indicators for breast cancer care in China. Int J Qual Health Care 2015;27:291-6.

21. Bland JM, Altman DG. Statistics notes: Cronbach's alpha. BMJ 1997;314:572.

22. Slootweg IA, Lombarts KM, Boerebach BC, et al. Development and validation of an instrument for measuring the quality of teamwork in 
teaching teams in postgraduate medical training (TeamQ). PLoS One 2014;9:e112805.

23. Zlateva I, Anderson D, Coman E, et al. Development and validation of the medical home care coordination survey for assessing care coordination in the primary care setting from the patient and provider perspectives. BMC Health Serv Res 2015;15:226.

24. Schopper D, Torres AM, Pereira J, et al. Setting health priorities in a Swiss canton: what do different methods tell us? J Epidemiol Community Health 2000;54:388-93.

25. Veerman JL, Barendregt JJ, Mackenbach JP. Quantitative health impact assessment: current practice and future directions. $J$ Epidemiol Community Health 2005;59:361-70.

26. Hwang CL, Yoon K. Multiple attribute decision making: methods and applications. Berlin, Germany: Springer, 1981.

27. Sun ZQ. Medical Statistics (2nd ed): Beijing, China: People's Medical Publishing House, 2005:514-8. (in Chinese).

28. Zaboli R, Tourani S, Seyedin SH, et al. Prioritizing the determinants of social-health inequality in iran: a multiple attribute decision making application. Iran Red Crescent Med J 2014;16:e12607.

29. Bai ZY. An interval-valued intuitionistic fuzzy TOPSIS method based on an improved score function. ScientificWorldJournal 2013;2013:1-6.

30. Shabaninejad H, Mehralian G, Rashidian A, et al. Identifying and prioritizing industry-level competitiveness factors: evidence from pharmaceutical market. Daru 2014;22:35.

31. Kuo RJ, Wu YH, Hsu TS. Integration of fuzzy set theory and TOPSIS into HFMEA to improve outpatient service for elderly patients in Taiwan. J Chin Med Assoc 2012;75:341-8.
32. Shen M, Zeng N, Hu J, et al. [Weighted TOPSIS method and weighted RSR method in the construction of drug supervision and supply networks in rural areas of Hunan]. Zhong Nan Da Xue Xue Bao Yi Xue Ban 20132013;38:301-6.

33. Wang $\mathrm{M}$, Fang $\mathrm{H}$, Bishwajit $\mathrm{G}$, et al. Evaluation of rural primary health care in Western China: a cross-sectional study. Int J Environ Res Public Health 2015;12:13843-60.

34. Wang H, Song P, An L. Comprehensive evaluation of the situation of maternal health care with TOPSIS and RSR. China J Health Statis 2015;32:240-2. (in Chinese).

35. Wang Z, Dang S, Xing Y, et al. Applying rank sum ratio (RSR) to the evaluation of feeding practices behaviors, and its associations with infant health risk in rural Ihasa, tibet. Int $J$ Environ Res Public Health 2015;12:15173-81.

36. Statistical Communique on the National Economic and Social Development (Year 2015) of Furong District. Statistical Information of Changsha city (Hunan province, China). http://www.cstj.gov.cn/ndqx/ index.jhtml (accessed $21 \mathrm{Jul}$ 2016).

37. Statistical Communique of Hunan province on the National Economic and Social Development (Year 2015). The People's Government of Hunan province. China. http://www.hunan.gov.cn/2015xxgk/ szfzcbm_8834/tjbm_6941/tjgbzb/201603/t20160318_2964470.html (accessed 21 Jul 2016).

38. Reply on Wuling Mountain Area Regional Development and Poverty Alleviation Plan (2011-2020) by the State Council of China. http:// www.seac.gov.cn/art/2013/3/18/art_6497_179231_1.html (accessed 21 Jul 2016). 